(Aus der Universitäts-Augenklinik zu Heidelberg)

\title{
Spontanruptur der hinteren Linsenkapsel nach doppelt perforierender Eisensplitterverletzung.
}

Von

\author{
kgl. bayer. Oberarat Dr. R. v. Heuss, \\ ehemaligem Volontärassistent der Klinik.
}

Mit Taf. I. Fig. 1 u. 2.

Die Linsenkapsel stellt ein Gebilde dar, das mit am längsten der destruierenden Wirkung intraokularer Eiterungen Widerstand zu leisten vermag. Sehen wir doch öfters in Augen, deren Contenta dem höchsten Grad eitriger Einschmelzung anheimgefallen sind, die allseitig von Eiter umspülte Linsenkapsel makroskopisch und mikroskopisch intakt.

Gleichwohl wird unter geeigneten Bedingungen auch die Linsenkapsel von dem eitrigen Prozess angegriffen. Zarte Eindrücke der Kapseloberfläche, hervorgerufen durch die innige Auflagerung eitriger Membranen, flächenhafte Arrosionen, tiefergehende circumscripte Macerierung, die in ihrer höchsten Stufe zur Perforation der Kapsel führt, endlich noch völlige Einschmelzung der ganzen Kapsel und ihres Inhaltes: dies sind die einzelnen Stadien des Auflösungsprozesses, welchem die Linsenkapsel bei intraokularen Eiterungen unterworfen sein kann.

Nicht bäufig gelangen diese pathologisch-anatomischen Veränderungen der Linse und ihrer Kapsel zur Beobachtung. Wenigstens ist die darauf bezügliche Ausbeute der Literatur eine verhältnismässig spärliche zu nennen. Gleichwohl würde es verfehlt sein, hieraus einen Rückschluss $\mathrm{zu}$ ziehen auf die Häufigkeit der in Rede stehenden Linsenaffektionen. Es ist vielmehr anzunehmen, dass die eitrige Zerstörung der Linsenkapsel in einer Reihe von Fällen gar nicht zu mikroskopisch wahrnehmbarer Entwicklung gelangt, da vorher der Prozess auf operativem Wege kupiert wird. 
Bei dem Interesse, das die hier zu besprechende Kapselaffektion darbietet, sei der Mitteilung meines Falles eine Darstellung des gegenwärtigen Standes unserer Kenntnisse über diesen Gegenstand rorausgeschickt. Ich beginne dabei mit einer Übersicht über die diese Fragen betreffenden experimentellen Untersuchungen und lasse derselben eine Zusammenstellung der vorliegenden pathologisch-anatomischen Untersuchungen von menschlichen Augen mit eitriger Linsenkapselperforation folgen. Es wird hierbei kein Anspruch auf Vollständigkeit gemacht. Die mitgeteilte Beobachtungsreihe erscheint jedoch ausreichend, um bei der Verschiedenheit der Entstehungsweise der einzelnen Fälle das Thema von verschiedenen Seiten zu beleuchten.

Woron es im gegebenen Falle abhängt, ob die Linsenkapsel unversehrt bleibt oder dem Eiterungsprozess unterliegt, bedarf noch weiterer Aufklärung. Intensität und Dauer der Eiterung, Menge und Wirkungsweise der Mikrobien, Lokalisation der Eiterung - ob im Glaskörper oder in der vorderen Kammer -, können hier von Einfluss sein. Die eigentlich wirksamen Faktoren und die Art und Weise ihrer Wirkung können wohl nur durch experimentelle Untersuchungen festgestellt werden; diese haben aber bisher noch keine ganz ausreichende Aufklärung gebracht.

Unsere heutigen Kenntnisse über die eitrige Erweichung und Auflösung der Linsenkapsel hat Th. Leber (9) 1891 in seinem Werk über die Entstehung der Entzilndung zusammengefasst und neue Beobachtungen hinzugefügt. Es sei die betreffende Stelle hier wörtlich angeführt, weil seitdem kein weiterer wesentlicher Fortschritt unserer Kenntnisse in dieser Richtung $\mathrm{zu}$ verzeichnen ist.

Ausgehend von der Aspergillus-Keratitis hatte Leber den Nachweis geliefert, dass die eitrige Erweichung und Einschmelzung der Gewebe, für welche er den Namen "Histolyse" einführte, durch einen von den Leukocyten ausgehenden chemischen Vorgang bewirkt wird, der einer Verdauungawirkung gleich zu setzen ist. Er hatte eine solche Wirkung in bezug auf die Linsenkapsel schon früher vermutet und der gelieferte Nachweis der Histolyse gab dieser Vermutung nun einen festeren Anhalt. Es war aber nicht ausgeschlossen, dass auch die Mikroorganismen einen ähnlichen Eínfluss auf die Linenkapsel ausüben. Es wurde daher von ihm der Anteil, der Leukocyten und Mikroorganismen bei diesem Vorgang zuzuschreiben ist, einer genaneren Erwägung unterzogen, bei weleher er sich folgendermassen ansspricht: „Anch die Linsenkapsel wird in gleicher Weise angegriffen; nur ist dabei vorläufig noch nicht zu entscheiden, wie weit es sich um eine Arrosion durch Eiterkörperchen oder durch Mikroorganismen handelt, weil alle bisher darïber aufgeștellten Beobachtungen Entzündungen mikrobischen Ursprunges betrafen. Es kommen ganz umselriebene Erweichungen und Perforationen der Kapsel vor, zum Teil nur von mikroskopischen Dimen- 
sionen, die von Eiterzellen ansgefüllt sind, aber nur spärliche Mikroorganismen erkennen lassen; ich möchte deren Entstehung so erklären, dass zunächst eine kleine Mikrobieninvasion entsteht, welche die Leukocyten herbeizieht, dass aber vorzugsweise die an der Stelle angesammelten Leukocyten die Erweichang and die Usur der Kapsel bewirken."

Über die früheren Untersuchungen wird dort bemerkt, es sei längst bekannt, „dass bei intraokularen Eiterungen zuweilen Eiterkörperchen in der Linse gefunden werden, die nur von aussen eingedrungen sein können, da nach den darüber angestellten Untersuchungen eine Entstehung von Eiterzellen aus Linsenelementen oder Kapselzellen mit Sicherheit auszuschliessen ist. Für die Mehrzahl der Fälle ist die Möglichkeit des Eindringens von Eiterkörperchen dureh eine Verletzung der Linsenkapsel gegeben; für die seltenen Fälle, wo Eiterkörperchen bei spontan entstandener eitriger Entzündung im. Inneren den Linse gefunden werden, blieb aber zu entscheiden, ob dieselben die intakte Kapsel durchwandern, oder ob sie durch Erweichung und Zerstörung der Kapsel Zutritt zur Linse finden".

Von den hier in Betracht kommenden Untersuchungen sei hier zunächst über die Versuche von J. Sinclair (1) berichtet, welche das Auftreten von Erweichung und Usur der Linsenkapsel bei intraoknlaren Eiterungsprozessen wohl zuerst experimentell erwiesen hat. Bei ihren Untersuchungen "zur Genese erworbener Kapselkatarakt" stellte Sinclair folgende Versuche an:

1. Versuch: Einbringen von $1 / 2 \%$ Kochsalzlösung, in welcher Zinnober suspendiert war, in die Vorderkammer - keine Wirkung auf die vordere Linsenkapsel.

2. Versuch: Injektion von frischem defibriniertem Kaninchenblut - kein Effekt.

3. Versuch: Injektion von gutartigem Eiter in die Vorderkammer kein Effekt.

4. Versuch: Injektion von defibriniertem Blut, welches in Zersetzung begriffen war: Im Pupillargebiet anf der vorderen Linsenkapsel ein 0,13 mm hoher Belag, der aus geschrumpften und zerfallenen Blutkörperchen, ziemlich viel Fibrin und spärlichen Eiterkörperchen besteht und leicht ablösbar ist. Der an den Belag grenzende änssere Kapselkontur ist weniger scharf und glatt als an der normalen Linse. Hier und da Quellung mässigen Grades im Bereiche des Belages.

Bei einem weiteren Versuch, Injektion von Eiter aus Wirbelcariesabscess: Linse von dichtem eitrig fibrinösen Belag bedeckt. Nach Abheber dieses Belages zeigt sich die änssere Grenzlinie leicht zackig infolge von Eindrücken, welche die Belagzellen an dex Aussenfläche hervorgebracht haben. Wird der letzte Versuch bis auf 30 Stunden ausgedehnt, so befindet sich das Auge im Zustande ansgedehnter Panophthalmitis. Die vordere Kapselfläche ist ausserordentlich uneben, wie zerklüftet; die Unebenheiten haben Ähnlichkeit mit dem Aussehen How shipscher Lacunen; dadurch ergeben sich Veränderungen bzw. Stellen, wo die Kapsel bis auf $0,01 \mathrm{~mm}$ verdünnt ist.

J. Sinclair schliesst: es ist sehr wohl denkbar, dass eine solche Usur sozusagen auf mikroskopisch kleine stellen beschränkt bleibt. Durch solche Stellen kann dann eine Einwanderung von Eiterzellen in den Kapselsack 
stattfinden; diese können daselbst perforieren. Eine Annahme, die zwar über die Entstehung der Usurstellen keinen Aufschluss gibt, aber wohl geeignet ist, das schon früher beobachtete Vorkommen von Eiterkörperchen innerbalb der Linsenkapsel bei spontan entstandenen Eiterungen zu erklären.

Es kann nach unsern heutigen Kenntnissen nicht wundernehmen, dass bei diesen Versuchen bakterienfreie Sekrete und Substanzen: Zinnober und Blut usw. der Linsenkapsel nichts anzuhaben vermochten. Über eine etwaige Wirkung der Mikroorganismen gestatten sie aber kein sicheres Urteil, da "gutartiger" Eiter (der doch wohl ebenfalls Mikrobien enthalten hat) ohne Einfluss war, während andere mikroorganismenhaltige Substanzen: in Zersetzung begriffenes Blut, Abscesseiter usw. die erwähnten Kapselusuren hervorriefen.

Die Versuche von Deutschmann(4), bei welchen er durch Injektion von Eiter in die Vorderkammer oder in den Glaskörper eitrige Entzïndung erregte, haben die Annahme von J. Sinclair bestätigt, dass dabei nicht nur eine lokale Erweichung, sondern auch eine Perforation der Linsenkapsel entstehen kann, welche den Eiterkörperchen Zutritt verschafft.

Deutschmann konnte bei seinem experimentell erzeugten intraokularen Eiterungen folgende Veränderungen der Linse beobachten:

1. Früheste makroskopische Veränderung: Mattigkeit der Linsenkapsel im Bereich der Pupille infolge oberflächlicher Arrosion. Die Kapsel erscheint wie angenagt, fein aufgesplittert und aufgefasert und mit Eiterkörperchen sowie mit Fibrinresten belegt. Vorderes Kapselepithel, sowie der ganze Rest der Kapsel selbst und die Linsensub$\operatorname{stanz}$ völlig intakt.

2. Stadium. Makroskopisch: Kleine punktförmige gelbe Eiterherde in der Linse selbst, in der vordersten Corticalis, dicht innerhalb der Kapsel bei sonst klarer Linsensubstanz. Mikroskopisch: hocbgradige Kapselverdünnung und Auflockerung, sowie punktförmige Durchlöcherung im Bereiche des Pupillargebietes; über den Eiterherden in der Linse das vordere Kapselepithel zerstört, in Detritusmasse umgewandelt; Epithel nicht mehr nachweisbar. Die gelben Punkte in der vorderen Corticalis bestehen aus Eiterkörperchen, nebst Detritusmassen von Linsenfasern und vorderen Epithelien. - Auftreten feinster Vakuolen in den Fasern. Ausserdem grosse, mit Myelintropfen angefüllte Zellen. Lymphkörperchen, die das aus den Linsenfasern ausgetretene Myelin in ihre Leiber aufgenommen haben. - Kein Perforationsvorgang.

3. Stadium. Weitere Verdünnung des Kapselsackes, fortschreitende Infiltration der Linse mit Eiterkörperchen, derart, „dass die Linse eine wirklich schwappende Blase darstellt, die beim Anstechen Flüssigkeit austreten lässt".

Mikroskopisch: Der beim Anstechen entleerte Tropfen besteht aus Eiterkörperchen, myelinhaltigen und myelinfreien, und Linsendetritus und Reste von Linsenfasern.

Ausserdem gelang der Nachweis, dass Eiterkörperchen in der Kapsel selbst steckten, und damit ward es zur Gewissheit, dass Eiter in die Linse nur von aussen gelangen könne, indem die Eiterkörperchen sich ihren Weg durch die Kapsel bahnten. 
Die gleichen Veränderungen spielten sich an der hinteren Linsenkapsel $\mathbf{a b .}$

Ganz besonders hebt Deutschmann das Verhalten der Linsenkapsel gegenüber dem Eiter in jenen Stadien hervor, in denen sich makroskopisch noch gar keine Veränderung wahrnehmen liess. "In solehen Fällen erwies auch das Mikroskop, vielleicht abgesehen von leichter beginnender Kapselusur, die Hauptpartie der Kapsel, sowie die ganze Linse intakt. Zeigte sich auch die Aussenfläche der Linsenkapsel dicht mit Eiter belegt, kein einziges Eiterkörperchen war an den Stellen, wo die Kapsel intakt oder eben nur oberfächlich angenagt war, durch dieselbe hindurehgewandert. Kein einziges fand sich innerhalb des Kapselsackes; niemals zeigte sich dabei auch nur eine Andeutung eines Proliferationsvorganges in Kapselepithelien oder Linsenfasern; Eiterk örperchen fanden sich immer erst dann in der Linse, wenn die Kapselusur und mikroskopisehe Durchlöcherung den Durchtritt von derartigen Elementen von aussen her gestattete."

Ähnliche Befunde ergaben die experimentell erzeugten chronischen Eiterungen. Als Material dienten tuberkulöse Produkte, die in die Vorderkammer oder den. Glaskörperraum eingebracht wurden.

Der Prozess an der Linsenkapsel spielte sich natïrlich entsprechend langsamer ab. Er befiel diejenigen Kapselpartien, in deren nächster Umgebung das Impfmaterial eingebracht war: die vordere Kapsel, wenn die vordere Kammer, die hintere Kapsel, wenn der Glaskörperraum infiziert wurde. In letzterem Fall ergab sich dabei der eigenartige Befund von Wucherungsvorgängen des vorderen Kapselepithels. Geben diese experimentellen Befunde von Deutschmann anatomisch ein klares. Bild der fruhhesten Stadien beginnender Kapselusur, so war damit die Frage, welcher von beiden Faktoren - Leukocyten und Bakterien - als primäres Moment an der Usurierung der Kapsel beteiligt sei, noch nieht gelöst. Es blieb fraglich, ob die Bakterien und von ihnen gebildete Enzyme das Agens darstellten, welches die Kapselsubstanz. angriff und auflöste, um dadurch den Leukocyten den Weg zu bahnen: oder aber, ob die Leukocyten, deren bistolytische Wirkung später voa Leber dargetan wurde, zuerst die Kapselsubstanz erweichen, um dann für sich, oder gemeinsam mit den Bakterien in dem destruierten Gewebe vorzudringen und seine vollige Zerstorung bis zar Perforation herbeizufuhren.

Das Eindringen der Leukocyten in die Kapsel auf rein mechanischem Wege lehnt Deutschmann (loc. cit.) ab mit dem Hinweis darauf, dass die Linsenkapsel an und für sich ein ausserordentlich festes Gefüge besitze, dass es ferner niemals gelang, Eiterkörperchen innerhalb der Linsenkapsel zu finden, wenn nicht schon die Kapsel arrodiert war. Auch die Erwägung, dass die Bakterien den Weg für die Eiterkörperchen bahnten, schien nicht zutreffend. Um die Vermutung Lebers zu prüfen, dass chemische Einflüsse, nämlich Ausscheidung eines Stoffes von seiten der Eiterkörperchen eine aufösende Wirkung ausüben können, wurden in dieser Richtung Versuche von Deutsehmann angestellt, die jedoch negativ ausfielen. Bei der Unvollkommenheit der damaligen Untersuchungsmethoden überrascht dies. 
nicht. Später ist, wie schon oben angegeben worden, die histolytisehe Wirkung der Eiterkörperchen von Th. Leber für andere Gewebe sicher erwiesen worden.

Zur Stütze seiner Annahme über den Hergang beruft sich Leber noch auf weiter unten genaner mitzuteilende Befunde Wagenmanns bei der Glaskörpereiterung des mensehlichen Auges. Es fanden sich, abgesehen von grösseren Lüicken, in mehreren Fällen mikroskopische Perforationsstellen, in welchen einzelne Eiterzellen oder Gruppen von solehen und auch Cokken eingelagert waren. Er gibt Wagen man $n$ Recht, dass die Bilder ganz den Eindruck machten, als ob zuerst die Cokken in die Kapsel eingedrungen seien und die Eiterkörperchen nach sich gezogen haben, und bemerkt dann: man würde sonst nicht wohl erklären können, warum auch in Fällen, wo die ganze Kapsel in Eiter eingebettet ist, so umschriebene Perforationen vorkommen, und warum die Kapsel hier nicht in meln gleichmässiger Weise der Wirkung der Eiterzellen erlegen ist, woza es bei weiter gediehenem Prozess unter Umständen wobl ebenfalls kommen wird.

Schliesslich führt Leber zur Illustration des Gesagten noch einen Befund an, der seines charakteristischen Bildes halber hier eingefügt werden muss: nach Einspritzung von Faulflüssigkeit in den Glaskörper des Kaninchens fand sich nach 13 tägiger Daner des Prozesses bei der Sektion auf der vorderen Linsenkapsel im Bereich der Pupille eitriges Exsudat; die Linse war getrübt, der Glaskörper eitrig infiltriert. Die hintere Linsenkapsel war teilweise zerstört und Eiterzellen von hinten her in die Linsensubstanz eingedrungen. Der Kiterbelag der vorderen Kapsel wurde vorsichtig abgestreift, die ganze Membran flach ausgebreitet und nach Fuchsintinktion in Balsam untersucht. Sie zeigt $7-8$ rundliche oder längliche, etwas unregelmässig begrenzte Löeher von $1 / 2$ bis $11 / 2 \mathrm{~mm}$ Durehmesser, die mit Eiter ausgefullt sind. Zwischen den Eiterzellen finden sich unregelmässig gestaltete Trümmer von Kapselsubstanz. Der Eiter enthält zahlreiche zerstreute, aber nirgends in Kolonien beisammenliegende Cokken. Noch weniger Cokken trifft man in der Kapsel selbst, in der Umgebung der Lücken und in den Kapseltrümmern, nirgends ist die Substanz dieht von Cokken durchsetzt, wie dies zu erwarten wäre, wenn diese die wesentliehe Ursache des Zerfalles der Kapselsubstanz abgegeben hätten.

Die soeben berichtete Hypothese Lebers scheint mir in der Beurteilung der Entstehung der spontanen Perforation der Linsenkapsel bei intraokularen Eiterprozessen einen Schritt weiter zu führen. Deutschmann vertritt noch, wenn man so sagen darf, einen unitarischen Standpunkt, d. h: er betrachtet Usurierung und Einschmelzung der Kapsel als einen Prozess, hervorgerufen durch eine Noxe - die Leukocyten - unter Beiseiteschiebung der Wirkung der Mikroorganismen. Wagenmann (7) lässt in seiner zeitlich später folgenden Arbeit die Frage unentschieden, sagt aber doch, es sei zweifelhaft, ob Leukocyten oder Mikrobien jedes für sich oder beide gemeinsam wirken. Leber zerlegt den Prozess in zwei Vorgänge: Zuerst 
Hineinwachsen der Mikroorganismen in die Kapsel an umschriebener Stelle, und sekundär infolge der chemotaktischen Wirkung der Mikrobientoxine Anziehung der Leukocyten und Anregung derselben zu histolytischer Wirksamkeit: dadurch Einschmelzung und Perforation der Kapsel. Er stützt diese Erklärung vor allem durch den oben mitgeteilten Befund in äusserst sinnfälliger Weise: die spärliche Verteilung der Cokken in der Kapsel und den zertrümmerten Partien im Gegensatz zu dem reichlichen Vorhandensein der Eitermassen.

Die diffuse Anordnung der Cokken, wie sie übereinstimmeud in sämtlichen Fällen gezeichnet ist, bei denen der Bakteriennachweis gelang, spricht eindeutig für die Annahme, dass hier die Cokkenwirkung in bezug auf die Kapsel zurücktritt gegenüber der histolytischen Wirkung der Eiterkörperchen. Vor allem lässt sich jetzt dadurch die Tatsache: dass in der, in ganzer Ausdehnung von Eiter umspülten Linsenkapsel nur ganz vereinzelte Löcher zu finden sind, ungezwungen erklären. Das war bisher unmöglich; und es schien vollkommen unverständlich, dass die Linsenkapsel, der in ganzer Ausdehnung Eitermasse innig angelagert ist, nicht auch wenigstens zum grössten Teil gleichmässig von den Eiterkörperchen angegriffen werden soll.

Auch am menschlichen Auge hat Th. Leber das Vorkommen eitriger Perforationen der Linsenkapsel anatomisch nachgewiesen und Wagenmann hat bei der spontanen Glaskörpereiterung des Mensehen den Vorgang der Kapselperforation, besonders in seinen Antängen an dem Material der Leberschen Klinik in Göttingen genauer untersueht. Die erste Beobachtung bezog sich auf einen schon im Jahre 1878 beobachteten Fall von spontaner eitriger Glaskörperinfiltration nach gut geheilter Glankomiridektomie, eine Affektion, die auf zufallige Infektion einer fistelnden Stelle der Operationsnarbe zurüekzuführen ist. Leber berichtete später gelegentlich, gestützt auf die dabei gemachten Untersuchungen, dass in solchen Fällen mitunter, wenn die Linse in der Nähe der Narbe liegt, die Linsenkapsel eine Arrosion erleidet und es zur spontanen Berstung der Linsenkapsel und Kataraktbildung kommt, wobei eitrig infiltrierte Linsenmasse die Höhlung der ektatisehen Narbe ausfüllt. Ich habe dies einmal nach einer Iridektomie wegen Glaukoma simplex gesehen, wo das Resultat anfangs ein völlig gutes war und der Patient hinterher genau beobachtet wurde, so dass kein Gedanke daran ist, dass bei der Operation eine Verletzung der Linsenkapsel hätte erfolgen können. Die eingehendere Mitteilung dieses Falles nebst der anatomischen Untersuchung Lebers findet sich in der grossen Arbeit von Wagen mann (7) über die von Operationsnarben und vernarbten Irisvorfällen ausgehende Glaskörpereiterung; dazu kommen zwei weitere Fälle, in welchen Wagenmann die dabei vorkommenden Veränderungen der Linsenkapsel genauer studieren konnte. 
1. Fall II. Eitrige Glaskörperinfiltration spontan an einem wegen Glaukom iridektomierten Auge aufgetreten. Dauer der Eikrankung: 4 Wochen.

Makrosk. Befund: R.: Ektasie der Operationsnarbe. Von ihr aus geht der Eiterprozess in die Tiefe. Die Keime erreichten den Glaskörper zwischen Linsenwand und Ciliarkörper. In der durch die Narbenektasie gebildeten Höhle liegt dichtes eitriges Exsudat und Linsenmassen, die von der geplatzten Kapsel hereinziehen. Die Linse ist platt, in ihrer unteren Hälfte stark verkleinert. Die Kapsel ist an dem der Narbe benachbarten Rand in ihrer Kontinuität unterbrochen. Die Enden klaffen weit auseinander, sind gefaltet und nach aussen umgeschlagen. Das Kapselloch ist breit, sein anderer Rand liegt erst jenseits des Colobomes. Aus diesem grossen Loch sind Linsenmassen ausgetreten und erstrecken sich mit Eiter untermischt in die Narbenhöhle. Die Linse ist in ihrer Substanz wenig verändert. Eiterkörperchen sind nur zwischen die Fasern eingelagert.

Epikrise: Dauer der Erkrankung bis zur Enucleation 4 Wochen. Eiterung, auf ektogenem Wege entstanden. Linsenkapsel an der dem stärksten Eiterstrome zunächst gelegenen Stelle breit perforiert. Wagenmann betont hierbei besonders: ein fernerer Beweis, dass von der Narbe aus der infektiöse Prozess seinen Ausgang genommen haben müsse, da hier die Linsenkapsel perforiert sei; diese Perforation sei allein als Folge der Eiterung aufzufassen. Eine Verletzung war auszuschliessen; eine solche hätte während der Nachbehandlung zur Beobachtung kommen müssen.

Es wurden Mikrobien im Glaskörper gefunden; in der Linse war aber der Nachweis negativ.

2. Fall XII. Eitrige Glaskörperinfiltration nach Staphylom. Links: Mikroskopisch: Der Glaskörper ist fast ganz gleichmässig in eine Eitermasse verwandelt. An der hinteren Linsenkapsel nahe am unteren Linsenäquator eine circumscripte frische Perforation der Kapsel durch den eitrigen Prozess erzeugt. Die Kapselenden sind nach aussen umgerollt und klaffen mässig breit. Ein das Kapselloch ausfüllender Eiterstreif ist im Begriff in die Linse einzudringen.

In der Linse fanden sich zwischen den von aussen eingewanderten Eiterhäufchen Cokken, ebenso zwischen den Linsenfasern. An der Perforationsstelle fanden sich am weitesten nach den Linsenfasern $z u$ in dem amorphen Eiweiss ganz massenhafte Cokkenkolonien. In einiger Entfernung nach aussen davon lagen die durch das Loch eindringenden Eitermassen.

Epikrise: Auch hier ektogene Infektion. Hochgradige eitrige Entzündung des Glaskörpers, wodurch eine frische Perforation entstand. Wichtig ist der Nachweis von Cokken in der Linse und der Hinweis, dass zuerst die Cokken, dann die Leukocyten nach der Linsenmitte zu gelegen sind.

3. Am interessantesten nun ist der folgende Fall XIII des gleichen Autors $^{1}$ ), bei dem es gelang, eine in der Entstehung begriffene spon-

1) Derselbe, loc. cit. S. $198 \mathrm{ff}$; Fall XIII, S. $208 \mathrm{ff}$. 
tane Kapselperforation zu studieren. Die Enucleation erfolgte wegen Panophthalmitis incipiens naeh peripherer vorderer Syneehie. Daner der Erkrankung ungefahr 21 Tage.

Mikroskopischer Befund: Die Cornea ist perforiert; die vordere Synechie frisch eitrig infiltriert; an ihrer dünnsten vorderen Stelle ein kleines frisches Vlcus, dessen Grund von freiliegender Iris und zurzeit eitrig filtrierten Narbengewebsfasern gebildet wird. Diese eitrige Masse zieht direkt in die Tiefe zur hinteren Kammer. Organisiertes, an Fibrin und Eiter reiches Exsudat füllt diese aus, liegt der Linse an und steht am Linsenäquator direkt im Zusammenhang mit dem eitrig infiltrierten Glaskörper. Der Eiter umgibt die Hinterfläche der Linse besonders dicht. Das vordere Kapselepithel der Linse ist an einigen Stellen gewuchert, liegt in mehreren Schichten übereinander, und stellt einen frischen Kapselstar dar.

„Neben vorderem Kapselstar Stellen mit nekrotischem Epithel. An einer circumscripten Stelle der vorderen Kapsel, nahe am medialen Äquator, eine beginnende spontane Perforation. Der Linsenkapsel daselbst schwartiges Gewebe aufgelagert, herrührend von früherer Entzündung und Eiter. An der Linsenkapsel eine circumseripte Einsenkung der Oberfläche; die letzte, benachbarte Auflagerungsschicht, die eine Art Deckmembran bildet, ist nach innen eingebogen. Vereinzelte Eiterkörperchen haben sich in die Kapsel eingesenkt; die Kapsel scheint an dieser Stelle erweicht; am Rand der kleinen Lücke erkennt man einen zum Teil geradlinigen, zum Teil gezackten Kontur. Man findet in diesem Loch ein oder zwei Eiterkörperchen stecken, dazwisehen ab und zu ein rotes Blutkörperchen und vereinzelt frei Pigmentkörner. An einer Stelle ist offenbar die erweichte Masse geschwunden, dort klaffen die beiden Enden, ohne Zwischensubstanz zu besitzen. Die Eiterkörperchen zwängen sich zwischen Linsenkapsel und Epithel. Einzelne Cokken liessen sich an der Perforationsstelle auch zwischen Epithel- und Linsenkapsel nachweisen.

Ob Cokken zuerst eindrangen und Eiterkörperchen nach sich zogen, ist nicht nachweisbar.

4. Schon vorher (1887) hatte Wagenmann(6) hierhergehörige Beobachtungen mitgeteilt in seiner Arbeit: "Utber einen Fall von doppelseitiger metastatischer Ophthalmie im Puerperium dureh multiple Streptocokkenembolie".

37jährige Frau, Krankheitsdauer ungefähr 16 Tage. Dauer der Augenaffektion ungefähr 11 Tage. Wegen Glaskörpertrübungen Spiegelbefund nicht anfzunehmen.

Pathologisch-anatomischer Befund des linken Auges: „Die vordere Linsenkapsel intakt..., die hintere Linsenkapsel ist in einer Reihe von Präparaten perforiert. Etwas eitriges Exsudat liegt in dem Riss. Der Glaskörper ist an dieser Stelle ziemlich stark eitrig infiltriert. Es ist nicht sicher zu sagen, ob die Perforation im Leben bestanden hat oder artifiziell ist; für letztere sprechen die scharfen Bruchenden der Linsenkapsel. - Dicht 
hinter der Pars eiliaris retinae beginnt aussen wie innen eine fast totale, nicht selur vorgewölbte Ablösung der Netzhant; diese zum Teil eitrig zerfallen... Glaskörper fast total abgelöst. In ihm Anfänge einer eitrigen Infiltration mit circumseripten Herden, in denen die Eiterung einen höheren Grad erreicht hat; Durehtränkung des Glaskörpers mit Fibrin, das in verschiedener Form Gerinnung eingegangen ist... Von diesen Eiterherden aus ziehen einzelne Züge von dieht gedrängten Eiterkörperchen nach der Fossa patellaris zu und reichen bis an die Linsenkapsel; im ganzen ist die eitrige Infiltration noch sehr gering.

Bakterienfarbung positiv: Enorme Massen von Streptocokken im Glaskörper, besonders in den peripheren Schichten und an jenen Stellen, wo die pathologischen Veränderungen einen höheren Grad erreieht haben. Im vorderen Teil des Glaskörpers, der Ciliargegend entsprechend, hat die Vermehrung der Organismen einen hohen Grad erreicht. Bis an die Fossa patellaris sind die Cokkenzüge ron eitrigem Exsudat begleitet zu verfolgen.

Epikrise: Auf endogenem Wege kommt es zu einer metastatischen Ophthalmie mit reicher Einwanderung von Cokken und verhältnismässig geringer Eiterentwicklung. Die Menge der Cokken erreicht nachweislich in der Nähe der hinteren Linsenkapsel nad des Corpus ciliare ihre grösste Ausdehnung. Hier finden sich anch die stärlssten pathologischen Veränderungen und mit ihnen die Perforationsstelle der Linsenkapsel. Ein dichtes Cokkenband, glaskörperwärts von dichtem Fibrinnetz begrenzt, liegt hier der Linsenkapsel an. Die Eiterkörperchen sind nur spärlich vorhanden. Unter diesen Verhältnissen erscheint es doch nahe liegend, eine vitale Perforation der Kapsel anzunehmen, die primär durch die enorme Masse der Cokken und deren Toxinwirkung zu stande gekommen ist.

5. In einem gleichen Falle von metastatischer Ophthalmie im Puerperium bedingt durch Streptocokkenembolie kann sich Vossius (8) eindeutig für eine spontane intra vitam erfolgte Kapselruptur aussprechen.

Dauer der Erkranknng: 6 Tage, der Augenaffektion 4 Tage.

Es handelte sich um eine komplizierte Entbindung. Am Tage nach der Entbindung Einsetzen der entzündlichen Erscheinungen am rechten Auge, die sich bis zu völliger Erblindung steigern. Am 6. Tage Exitus letalis. Enucleatio bulbi post mortem. Der makroskopische Befund bestätigt unter anderem die klinisehe Diagnose auf Luxation der Linse nach hinten. Der Glaskörperraum war gegen die hintere Augenkammer durch einen quer von der Ora serrata der einen zur andern Seite ausgespannten straffen, ganz intakten Gewebsstreifen getrennt. In dem in eine vordere und hintere Hälfte zerlegten oberen Bulbusabschnitt fand sich ein ausgedehnter, mit einer glatten Membran ausgekleideter Hohlranm. Die Membran stellte die geplatzte Kapsel der in den Glaskörperraum luxierten Linse dar. Die Retina war fast völlig degeneriert und in einen eitrigen Streifen umgewandelt. Zwischen Retina und Chorioidea gelatinöses Exsudat. Im Glaskörper eine dichte Infiltration mit Eiterkörperchen, zwischen denen reichliche Streptocokkenmassen gelegen waren. Beide 
gingen direkt auf die Processus ciliares über. Circumscripte Eiterherde waren im Glaskörper nicht nachweisbar. Um die Linsenkapsel herum befand sich ein volliges Eiterkörperchenlager, durchsetzt von roten Blutkörperchen und Streptocokken. Dieselben Bestandteile zeigte die die Linsenkapsel ausfüllende Masse, in welche der Linsenkörper eingebettet war. Auch die übrigen Teile des vorderen Augenabsehnittes zeigten reichliche Eiterinfiltration und enorme Massen von Streptocokken, die zum Teil im Gewebe, zum Teil in den Gefässen sich darstellen liessen.

Epikrise: Bei einer septisehen Puerpera tritt am 2. Tage nach der Entbindung eine einseitige eitrige Ophthalmie auf, die innerhalb von 4 Tagen einen ausserordentlich stürmischen Verlauf nimmt. Der okulare Krankheitsprozess dauert im ganzen 4 Tage. Es kommt ausser zu einer hochgradigen Eiuschmelzung der inneren Augenhäute zu einem Defekt der Zonula und Luxation der Linse. Dass beide Erscheinungen vor Erkrankung des Auges nicht bestanden, konnte noch bei der erstmaligen Untersuchung, dann auch durch die Anamnese festgestellt werden. Ob die Ruptur der Kapsel und die Eiteransammlung im Kapselsack schon vor der Versenkung der Linse in den Glaskörperraum bestanden habe, will Vossi us nicht entscheiden. Um so bestimmter hebt er jedoch die 'Tatsache hervor, dass die Kapselruptur nicht artifiziell, sondern im Leben entstanden sei, „wie die Anwesenheit der grossen mit Streptocokken untermischten Eitermasse beweist, die sich aus der Umgebung direkt in den Kapselsack fortsetzte".

Was die Ursache der Ruptur angeht, so vertritt Vossius den gleichen Standpunkt wio Deutschmann and Wagenmann: die Einwanderung von Eiterkörperchen in den Kapselsack findet nur durch mikroskopische oder makroskopische Usurstellen der Kapsel bei intraokularen Eiterungen statt. - Wie diese Usur zu stande kommt, darüber spricht Vossius keine Vermutung aus.

6. In einem weiteren Fall von Eiterung im Anschluss an vernarbte Irisvorfälle konnte Wagenmann (10) Perforation sowohl der vorderen wie der hinteren Linsenkapsel feststellen. Dauer des eitrigen Prozesses ungefähr 17 Tage.

Aus dem mikroskopischen Befund ist hervorzuheben: "Die Eiterung setzt sich von dem Prolaps unmittelbar auf den Glaskörper fort, der in seinem vorderen Teil überaus dicht eitrig infiltriert ist, während in den hinteren Abschnitten massenhafte Fibrinnetze neben mehr zerstreuter Infiltration vorkommen; dichte Eitermassen auf der vorderen und der ganzen hinteren Linsenkapsel. Vordere Linsenkapsel perforiert; die mit Eiter gemengten Linsenmassen setzen sich bis in die Höhlung des Irisvorfalles fort. Eine zweite Perforation zeigt die hintere Linsenkapsel, durch welehe Eiterkörperchen eingedrungen sind; die Kapsel ist in der Aquatorialgegend gefaltet, das Epithel daselbst gewuchert.

An den Perforationsstellen und in der Linse keine Cokken, während im Glaskörper und der Prolapshöhle solche reichlich vorhanden waren.

Besonders wichtig erscheint in diesem Falle, dass auch die hintere Linsenkapsel perforiert wurde. Der Glaskörper zeigt sich als beste Entwicklungsstätte der Mikroorganismen, die in Verbindung mit der besonders dichten eitrigen Infiltration die Kapsel umlagern und schliesslich zerstören. 
Diese in kurzem wiedergegebenen sechs Fälle stellen, abgesehen von den einschlägigen experimentellen Arbeiten, die Hauptausbeute aus der Linsenliteratur dar.

Zwei Fälle entwickelten sich im Anschluss an endogene, vier an ektogene Infektion, keiner ist hervorgerufen durch Fremdkörperverletzung. Allen Fällen gemeinsam ist die Lage der Kapselperforation entsprechend dem Ort der stärksten Eiterentwicklung. So liegt im Fall 1, in dem die stärkste Eiter- und Cokkenansammlung sich im Glaskörper befindet, die Perforation an der binteren Linsenkapsel, in Fall 4 und 5, wo die Infektion sofort an der Linse vorbei in die Tiefe zieht und sich im Glaskörper etabliert, ebenfalls an der hinteren Kapsel. In letzterem Falle kommt noch der interessante Befund einer frischen Epithelwucherung der vorderen Kapsel hinzu.

In Fall 3 und 6 liegt die Perforation in der vorderen Kapsel, dem primären Ort der Eiterung zunächst gelegen, ausserdem aber auch in diesen beiden Fällen an der hinteren Linsenkapsel, übereinstimmend mit der hochgradigen Infektion des Glaskörpers. Also immer da die Perforation, wo der eitrige Prozess und die Cokkenanhäufung zu stärkster Entfaltung kommen.

Die Form der Perforationsstellen ist zumeist die von kleinen, scharf begrenzten Löchern, die sich aber auch zu einer grösseren Spalte erweitern können; durch diese quillt dann die Linsenmasse vor.

In nächster Umgebung der Perforationsstellen, eventuell auch in diesen sind die Leukocyten und Cokken besonders reichlich gelagert. Cokken konnten in sämtlichen Fällen nachgewiesen werden; in einem Falle mit Bestimmtheit Streptocokken, in den eitrigen Fällen Cokken ron kleinerer und grösserer Form ohne besonders charakteristische, auf eine bestimmte Art hindeutende Lagerung.

Soweit die wenigen ausgeführten Befunde eine Beobachtung möglich machten, waren die Cokken den Leukocyten nach dem Linsenzentrum zu vorgelagert, schienen diesen also den Weg zu bahnen.

Die Dauer der für das Auge deletären Erkrankungen erstreckte sich über eine Spanne von mindestens 4 bis zu höchstens 22 Tagen.

Kein einziger der beschriebenen Fälle entstand im Anschluss an Fremdkörperverletzung; Fälle dieser Genese scheinen zu den Seltenheiten zu gehören. Der in folgendem mitzuteilende Fall von einem nach Fremdkörperverletzung zugrunde gegangenen Auge und der hierbei erhobene pathologisch-anatomische Befund 
interessierte deshalb um so mehr, da er ein geschlossenes Bild einer besonders charakteristischen spontanen Perforation der hinteren Linsenkapsel im Anschluss an eine doppelt perforierende Eisensplitterverletzung. gewährt.

\section{Krankengeschichte.}

Einem Schlosser (I. W.) Hog am 16. VI. 1896, als er kaltes Eisen hämmerte, ein Fremdkörper gegen das linke Auge. In der folgenden Nacht Sehmerzen, deshalb am 17. VI. Aufnahme in die hiesige Universitäts-Augenklinik.

17. VI. Befund: Linker Bulbus stark eiliar injiziert. Cornea klar. In der vorderen Kammer ein $2 \mathrm{~mm}$ hohes Hypopyon. Am inneren oberen Irisrand fleckig.fädiges Exsudat. Pupille eng; erweitert sich mässig auf Homatropin.

Nach innen unten, etwa $3 \mathrm{~mm}$ vom Limbus entfernt, eine $2-3 \mathrm{~mm}$ lange meridional gerichtete Skleralwunde, deren Ränder nicht klaffen. Bei leicht geöffnetem Auge liegt derselben genau gegenüber eine leicht klaffende Wunde des Lidrandes, die wie eine Scharte aussieht. Die Verbindung beider Wunden durch eine Gerade würde in der Verlängerung den Fundus unterhalb der Pupille treffen. Im Glaskörper eine graue wolkige Masse, wahrscheinlich Blut. Pupille verschleiert sichtbar. Gerade nach unten unter derselben eine schwärzliche, nicht prominente Stelle, umsäumt rou weisslichem Hof, an den sich nasalwärts eine Blutung anreiht. Die Stelle sieht aus wie eine Chorioidealruptur. S. = Finger in $3 \mathrm{~m}$. Therapie: Atropin, Verband, warme Umschläge.

18. VI. Hypopyon kleiner. Aus der Pupille gelber Reflex. Keine Details mehr zu erkennnen. Keine Schmerzen. $\mathrm{S}$.=Finger in $2 \mathrm{~m}$.

19. VI. Dicker gelber Reflex aus der Tiefe. S.=Handbewegung in $1 / 2 \mathrm{~m}$. Lichtschein für niederste Lampe. Projektion gut. Schmerzen.

20. VI. Zwei vertikal gestellte gelbe Wolken im Glaskörper. Keine

22. VI. Liehtsehein für nieđerste Lampe. Projektion nasal dubiös. Hypopyon nicht grösser geworden.

26. VI. Man unterscheidet jetzt deutlicher eine scharf begrenzte Eitermasse an der hinteren Kapsel und dann wolkiges, eitriges Exsudat im Glaskörper.

28. VI. Bulbus sehr druckempfindlich.

30. VI. Die eitrige Exsudation im inneren Bulbus nimmt zu.

3. VII. Liehtschein für niederste Lampe; Projektion nach oben fällt jedoch aus. Enucleation. Heilungsverlauf normal.

14. VII. 1896. Entlassung.

Das Kammerwasser des enucleierten Bulbus ergibt mit Loretin Eisenreaktion. Der in Formol fixierte Bulbus wurde in der Horizontalen in zwei gleich grosse Hälften zerlegt, in Alkohol.gehärtet und in Celloidin eingebettet.

Uber den makroskopisehen Befund wurde damals vermerkt: „2 Papillendurchmesser vertikal unter der Papille ein Fremdkörper von rötlichem Exsudat eingeschlossen, von da ein eitriger Strang durch den Glas- 
körper zur Eintrittsstelle des Fremdkörpers hinziehend. Retina stellenweise abgehoben."

Bei Lupenvergrösserung lässt sich an der unteren Bulbushälfte entnommenen Sehnitten folgendes feststellen: Die Durchmesser des Bulbus sind von normaler Grösse. Die Cornea ist intakt. Vorderkammer von normaler Tiefe. Die vordere Linsenkapsel ist leicht gefältelt; sie ist durehgehends durch einen schmalen Spalt von der eigentlichen Linsensubstanz getrennt, die im Aquator beiderseits klaffende Hohlräume aufweist. Die hintere Linsenkapsel zentral in breiter Ausdehnung durchbrochen; die Linsenmassen quellen durch diese Pforte nach dem Glaskörper hin vor und schmiegen sich abgerundet der linteren noch intakten Kapsel beiderseits von der Perforationsstelle an, so dass diese Linsenmasse eine pilzartige Gestalt erhält (siehe Tafel I, Fig. 1).

Vom Linsenäquator $a b$ ist der hinteren Linsenkapsel eitriges Exsudat angelagert, das auch das ganze Corpus ciliare besonders medial überkleidet und einen kegelartigen Fortsatz glaskörperwärts entsendet (Fig. 2). An der Abgangsstelle dieses Zapfens ist die Pigmentschicht des Corpus eiliare breit durchbrochen. An derselben Stelle wird eine sklerale Narbe deutlieh sichtbar. Die genannten Veränderungen weisen auf den Weg hin, den der Fremdkörper im Bulbus genommen lat. An Schnitten, die so tief liegen, dass von der Linse fast nichts mehr zu sehen ist, lässt sich das ganze Fremdkörperbett überblicken und erkennen, dass dasselbe die hintere Bulbuswand fast völlig durchsetzt. Von dem Fremdkörper selbst ist überraschenderweise nichts zu finden.

Der Eisensplitter hat also folgenden Weg zurüekgelegt: Derselbe trat nach unten und innen vom Limbus in die Sklera ein, passierte dieselbe in schräger Richtung und durchsetzte die hintere Hälfte des Corpus ciliare, hierauf den Glaskörper, gleichfalls in schräger Richtung, spaltete Ader- und Netzhaut, und drang in die Sklera ein, diese fast völlig perforierend. Die frühere Lage des Fremdkörpers ist sehr dentlich za erkennen als ein klaffender Spalt, der ringsum von einer braunen Rosteinlagerung: umgeben ist; die änssere Hälfte des Spaltes befindet sich in der Augenwand, die innere im Bereich des Glaskörpers. Die Ränder des so entstandenen Fremdkörperbettes stossen gegen den Glaskörper hin spitzwinklig zusammen und sind von Chorioidea und stark gefälteter Retina überkleidet. Die hinteren Wände des Bettes sind gegeneinander verschoben, so dass ein die Sklera nach aussen durchziehender Kanal entsteht. Intensive Eisenreaktion dieser ganzen Gegend weist auf ein längeres Verweilen des Fremdkörpers daselbst hin. Der Eisensplitter selbst war nicht mehr vorhanden. Die Verschiebung der skleralen Wundränder und die Tatsache, dass innerhalb des so entstandenen Kanales einzelne Eisenreaktion gebende Gewebsinseln nachzuweisen waren, lassen an eine gewaltsame Entfernung des Splitters denken, der vermutlich bei der Enucleation des Auges in der Orbita zurückblieb. Es ist anzunehmen, dass dieser vorher etwas prominierte und durch die Branchen der Enucleationsschere erfasst und aus dem Bulbus vollends heransgerissen wurde. Es ergibt sich hieraus, dass die ursprüngliche Angabe, laut welcher am frisch aufgeschnittenen Auge der Fremdkörper zu sehen war, auf Täuschung beruhte. Es handelte sich hier nur 
um das Fremakörperbett, dessen Form erhalten war und in seiner rostbraunen Verfärbung wohl als der Splitter selbst angesehen werden konnte.

Aus dem geschilderten Weg, den der Splitter durch den Bulbus nahm, lässt sich mit Sicherheit eine direkte Verletzung der hinteren Linsenkapsel ausschliessen.

\section{Mikroskopischer Befund.}

Die Perforationsstelle der Augenwand (vgl. Fig. 2) ist im wesentlichen verheilt, ohne dass es in ihrem Bereich zu einer nennenswerten Entzündung gekommen wäre. Nur im innersten Drittel etwa klaffen die beiden Wundränder etwas, der übrige Teil ist linear verheilt; an einzelnen Schnitten sieht man in der Gegend der Narbe ein weites Gefäss, das den grössten Teil der Dicke der Sklera schräg durchsetzt.

Die Lücke des Ciliarkörpers ist von ziemlich lockerem, neugebildetem Bindegewebe eingenommen, in welchem ebenfalls einige ziemlich weite klaffende Gefässe eingeschlossen sind. Nach einwärts setzt sich das Bindegewebe in einen Strang fort, der, wie oben beschrieben, den Weg des Fremdkörpers bezeichnet und in dem erwähnten Fremdkörperbett endigt.

Während nun die grössere hintere Hälfte dieses Stranges, ebenso wie auch das ganze Bett des Fremdkörpers von eitriger Exsudation ganz frei ist, wird der vorderste Teil des Stranges von einer dichten Zelleninfiltration eingenommen, welehe, sich nach hinten verschmälernd, allmählich aufhört und nach vorn gegen die Perforationsstelle des Ciliarkörpers zu ohne scharfe Grenze in das hier befindliche nengebildete Bindegewebe übergeht.

Diese Zellenanhäufung lässt zweierlei Elemente unterscheiden: dichtgedrängte, rundliche und sich gegenseitig abplattende Eiterzellen von blassvioletter Hämatoxylinfärbung, die im Inneren keinen deutlichen Kern erkennen lassen and offenbar nekrotisch sind; dazwischen eingestreut spärliche mehrkernige Leukocyten, deren Kerne mit Hämatoxylin sehr intensiv gefärbt sind.

An der Abgangsstelle dieses Stranges gegen den Glaskörper hin findet sich eine besonders reichliche Schicht dichter Fibrinnetze, die mit Eosin eine rötliche Färbung angenommen haben. Nach dem Glaskörper zu gehen sie in das lockere Fibrinnetz über, welches den vorderen Teil desselben in grosser Ausdehnung durchzieht. Weiter nach dem Ciliarkörper hin wird das Exsudat lockerer und es treten darin einkernige Zellen auf.

Eine zweite eitrige Infiltration findet sich im Bereich der hinteren Linsenfläche (vgl. Fig. 1 und 2). Sie hängt mit der bisher beschriebenen in der Weise zusammen, dass sich von der Ansatzstelle des Stranges aus in dem die Zonula und Hinterfläche der Linse deckenden neugebildeten Bindegewebe eine mässig eitrige Infiltration bis zur Mitte der Linse hinzieht.

Die Linse befindet sich in normaler Lage. Die vorderen und äquatorialen Kapselpartien verlaufen wellig und sind besonders am Äquator stark gefaltelt. Die hintere Linsenkapsel zeigt in der Mitte eine ziemlich ausgedehnte Lüeke (vgl. Fig. 1), deren Ränder beiderseits spiralig nach aussen anfgerollt sind. Die erhaltenen Partien der hinteren Kapsel sind intakt, vielleicht etwas verdickt. Die durch die Lücke vorquellenden Linsenmassen zeigen eine reichliche Eiterinfiltration, am stärksten die am meisten rorge- 
quollenen Partien, die sich seitlich anf die Kapselpartien umgelegt haben. In den mittleren Partien der extrakapsulären Linsenmassen ist die eitrige Infiltration nicht mehr zusammenhängend, abgesehen von der oberflächlichsten Schicht. Sie tritt hier in Haufen und Zügen auf, die sich zwischen den Linsenfasern nach einwärts erstrecken und die neben den Rändern der Perforationsstelle besonders dicht sind. Die eitrige Infiltration zieht nun auch in die Linse hinein bis an deren vordere Fläche. Je weiter nach einwärts und vorn, um so lockerer ist dieselbe; die Eiterkörperchen liegen zuletzt nur vereinzelt oder in kurzer einfacher Reihe zwiseben den Linsenfasem eingebettet. Sie erseheinen dabei blasig aufgequollen, ihre Randschicht hell, scharf von der umgebenden Linsensubstanz abgesetzt; nur in der Umgebung der Kerne ist etwas von körnigem Protoplasma wahrzunehmen.

Die Randzone der vorquellenden Linsenmasse ist von einem ziemlich lockeren Fibrinnetz umhüllt, das nur gegen.den Linsenrand hin dichter wird. Dasselbe geht wie die oben beschriebenen Fibrinnetze in das lockere Fibrin des vorderen Glaskörperteiles über, welehes von nicht sehr zahlreichen Leukocyten infiltriert ist. Da, wo die eitrige Infiltration der Linsensubstanz am dichtesten ist, ist das Linsengewebe selbst kaum mehr als solches zu erkennen. Es erscheint bei schwacher Vergrösserung als mit Eosin gefärbte Substanz, die zwisehen den Zellen verteilt ist. Wo die Eiterinfiltration lockerer wird, treten allmählich wellige Zïge rosagefärbter Linsenfasern zwischen den Zellenmassen hervor, dazwischen aber auch homogene Eiweisssubstanz, die dureh die Härtung geronnen ist.

Unterhalb der Rissstelle ist die Linsenkapsel vielfach eingeknickt; oberhalb stark wellig gefaltet. Circumseripte Läsionen oder das Eindringen einzelner Leukocyten in die Kapsel finden sich nicht.

Die übrigen entzündlichen Veränderungen finden sich hanptsächlich in der Cornea, Retina und Chorioidea einmal in der Höhe des Fremdkörperdurehganges durch die Sklera und das Corpus ciliare, ausserdem in der Gegend des Fremdkörperbettes.

Das Epithel der Cornea ist überall intakt. Die Bowmansche Membran buehtet sich in ihrem ganzen Verlaufe wellig gegen das Epithel vor. In diesen Buchten häufen sich Leukocyten an, die vereinzelt die genannte Membran durchdringen und sich in die hintersten Epithelsehichten einlagern. Die vorderen Schichten der Substantia propria sind ebenfalls von runden und spiessigen Zellen durchsetzt, deren grösste Anhänfung nach dem Limbus zu auftritt. Reiche Gefässbildung durehzieht die mittleren Schichten der Grundsubstanz, während hauptsächlich die Randzone der hinteren Schichten dicht von Eiterkörperchen infiltriert ist, die hier von der Gegend des Schlemmsehen Kanales und des Ligamentum pectinatum aus vordringen.

Am Boden der Vorderkammer lagert ein dichtes eitriges Exsudat. Oberhalb desselben sind der Membran. Descemet. und der Irisvorderfäche Eiterkörperchen teils vereinzelt, teils zu Klümpchen geballt, aufgelagert.

Die Iris ist stark hyperämiseh; in einzelnen Sehichten findet sieh um die Gefässe kleinzellige Infiltration. Näehst der Iriswurzel reichliehe Eiterkörpercheneinlagerung. Eine eigenartige Form gewinnt der Querschnitt der Iris dadurch, dass diese etwa am Ubergang von Pars pupillaris in die Pars 
ciliaris mit den ihr anliegenden stark gesehwollenen Processus eiliares verlötet ist und retrahiert wird (vgl. Fig. 2). Sonstige hintere Synechien bestehen nicht. In der durch diese Retraktion entstehende doppelseitige Einkerbung der Irisvorderfläche sind kleine Leukocytenhaufen eingefügt.

Auf der medialen Seite setzt sich die eitrige Infiltration des Kammerwinkels auf die vordere Hälfte des Ciliarmuskels fort und durchzieht diesen, immer geringer werdend, bis zum Fremdkörperkanal. Die Gefässe sind stark hyperämisch, zum Teil von Rundzellenanhäufungen umgeben. In der Umgebung des Wundkanals findet sich eine ziemlich starke Pigmenteinwanderung Die Veränderung in dem Ciliarkörper, welche diesem ein getigertes Aussehen verleihen, bestehen in spärlicher Rundzelleninfiltration um die erweiterten Gefässe, hauptsächlich längs der Pigmentschicht.

Die Processus eiliares sind stark geschwellt, vergrössert und dicht aneinandergedrängt; besonders die Firsten sind von mehrkernigen Leukocyten infiltriert, die sich auch durch den Epithelbelag in die Umgebung hineinerstrecken.

Das Pigmentepithel ist stellenweise sehr unregelmässig und zeigt verschiedenartig gestaltete Fortsätze, die besonders nach einwärts in die Schicht der pigmentlosen Zellen hineinragen. Vereinzelt zeigen sich die letzteren in deutlicher Proliferation begriffen. In den Kuppen mehrerer Ciliarfortsätze hat eine dichte Leukocyteninfiltration schon zu einem umschriebenen Schwund der pigmenthaltigen und pigmentlosen Schicht des Epithels gefuhrt.

Besonders stark ansgesprochen sind die Wucherungsvorgänge an der Pars ciliaris retinae. Die Zellen sind hier beträchtlich verlängert, gegeneinandergedrängt und hin und her gefaltet. Stellenweise ist auch die betreffende Schicht von den ebenfalls gewucherten Pigmentzellen durch eine anders aussehende bindegewebsähnliche Wucherung mit Gefässen emporgehoben.

Ein ähnliches, gleichfalls von Kapillaren dnrchzogenes Gewebe überzieht auch die Innenfläche der gewucherten Pars eiliaris und geht weiterhin in die Zonula über, indem es an den Firsten der Pars ciliaris vorbeizieht und mit denselben zusammenhängt.

Die oben beschriebene Bindegewebswucherung erstreckt sich von der Zonula aus auf beide Seiten der hinteren Linsenfläche, die in ihren seitlichen Partien in ganzer Ausdehnung in dicker Schicht davon überzogen wird; sie enthält ziemlich zahlreiche neugebildete Gefässe von kapillarem Charakter; dagegen bleiben die mittleren Linsenpartien von diesem Gewebe frei, wie sich an den oben beschriebenen, durch die Mitte der Linse fallenden Schnitten erkennen lässt.

An der Ora serrata ist es schon za einer beginnenden Einwärtszerrung der Retina durch die Retraktion des anliegenden Gewebes gekommen. Die Retina bildet bier eine cirkuläre Falte, war aber im Leben nicht in grösserer Ausdehnung abgelöst. Die vorbandene Ablösung der ganzen Retina von der Ora serrata bis zur Papille bzw. bis zum Fremdkörperbett ist artifiziellen Ursprunges.

Der Limitans interna liegen in ganzer Ausdehnung zerstrent, hier und da zu kleineren Klümpehen geballt, Eiterkörperchen auf. Hauptsächlich auf der Seite des Fremdkörperkanales, und von diesem abwärts bis in die Höhe 
des Fremakörperbettes findet sich meist auf die hintere Hälfte des Bulbus beschränkt eine starke Hyperämie der grösseren Gefässe der Retina und ihrer Kapillaren. Diese umgibt dichte kleinzellige Infiltration, die sich diffus in die weitere Umgebung der Gefässe erstreckt, im allgemeinen jedoeh an der Sehicht der inneren Körner Halt macht. Erst in der Nähe des Fremdkörperbettes verdichtet sich diese Lymphocyteninfiltration und dringt zum Teil vermischt mit spärlichen Leukocyten bis zur Schicht der äusseren Körner durch. Die Schicht der inneren Körner ist an solchen Stellen ganz auseinandergeworfen, bisweilen unter dem Druck der starken Rundzelleninfiltration fast verschwunden. - Die Gefässe des Sehnervenkopfes sind mässig erweitert, ihre Umgebung ist kleinzellig infiltriert. Die rückwärtigen Teile des Optikus sind von normaler Struktur.

Die entzündlichen Veränderungen der Chorioidea beschränken sich im wesentlichen auf eine hochgradige Hyperämie der Schicht der grossen Gefässe und der Choriocapillaris, so dass ein Unterschied zwischen beiden Schichten kaum festzustellen ist. Die erweiterten Gefässlumina sind dicht mit roten Blutkörperchen gefült, zwischen denen sich nur ganz selten ein polynucleärer Leukocyt findet. Eine eigenartige Rundzelleninfiltration tritt in mehr oder minder gleichmässiger Stärke in der ganzen Chorioidea auf. Während sich Lymphocyten in der Choriocapillaris in diffuser Anordnung nur spärlich zeigen, treten sie um die grossen Gefässe zu Haufen zusammen und umgreifen die ersteren von vorn und hinten. Diese Anordnung bleibt zumeist auf einzelne Gefässe beschränkt, kann jedoch auch derart sein, dass sie auf beiden Seiten bis zu dem nächsten grossen Gefäss weiter schreitet. Dann liegen die Rundzellen in parallelen Reihen entsprechend den Lamellen der Aderhaut, bald dünner, bald so dicht, dass sie gegeneinander abgeplattet werden. An solchen Stellen sind dann auch die pigmentierten Stromazellen sehr sehmal, in die Länge gezogen, im Schwinden begriffen. Ein Übergreifen der Rundzellen nach der Sklera oder durch die Glasmembran in die retinale Pigmentschicht ist nicht zu beobachten.

Was die Natur der infiltrierenden Zellen angeht, so handelt es sich um Lymphocyten, deren Kern die ganze Zelle einzunehmen scheint, dass ein Protoplasmaleib fast nie zu erkennen ist. An Orten, wo die Lymphocyteninfiltration mehr diffusen Charakter besitzt, treten auch vereinzelt epitheloide Zellen auf, doch nie in solcher Menge, dass sie gegenüber der Masse der Rundzellen überwiegen.

Der Bakterienbefund ist positiv. Der Nachweis gelang hanptsächlich nach der Weigertschen Methode, ausserdem auch nach langer Utberfärbung mit altem Delafieldschen Hämatoxylin und Gegenfärbung mit Eosin. Unsichere Resultate ergaben die andern üblichen Methoden.

Die Mikroorganismen haben Cokkencharakter. Der Hauptsache nach von rundlicher Form, sind sie zum Teil auch oval, im ganzen von verschiedener Grösse. Selten vereinzelt, treten sie meist unregelmässig zusammengelagert in kleineren Haufen anf. Tinktoriell verhalten sie sich insofern ungleich, als manche weit dunklere, die meisten blassere Farbung besitzen. - Der Ort ihres Vorkommens ist genau beschränkt. Sie finden sich frei in der Linsenmasse innerhalb der Linsenkapsel. Ferner in jenem dem Kapselriss angelagerten Konglomerat von Linsensubstanz und Eiter- 
körperchen, das oben eingehend beschrieben ist. Weiter glaskörperwärts ist der Befund negativ. Nur in einem Präparate fanden sich längs der intakten hinteren Linsenkapsel in dem dieser anliegenden bindegewebig organisierten Schicht zwei bis drei sich kaum färbende Cokkenhaufen. In dem ganzen Fremdkörperkanal, ebenso in der Umgebung des Fremdkörperbettes, auch in diesem selbst, liessen sich Cokken nicht nachweisen.

\section{Epikrise.}

Ein Eisensplitter von unbedeutender Grösse perforiert den Bulbus zweimal. Er durchdringt die Sklera nach innen vom Hornhautrand, durchsetzt schräg den hinteren Teil des Corpus ciliare und den Glaskörper, um unterhalb der Papille eingebettet zwischen den gespaltenen Augenhäuten liegen zu bleiben, deren äusserste er fast völlig durchtrennt hat. Das längere Verweilen des Splitters in der hinteren Bulbuswand lässt sich anatomisch sowohl als auch durch die Eisenreaktion nachweisen. Warum der Fremdkörper trotzdem nicht mehr vorgefunden wurde, wurde oben auf hypothetischem Wege zu erklären versucht.

Der Eintrittskanal ist durch bindegewebige Wucherumgen geschlossen. Ein eitriger Exsudatstrang zieht in seiner Verlängerung glaskörperwärts, ohne die Äquatorebene zu überschreiten. Starke Leukocyteninfiltration, zum Teil grössere nekrotische Partien des Exsudates weisen auf eine starke reaktive Entzündung hin, die mit dem Untergang der hier zweifellos primär aufgetretenen Mikrobien endigte. Processus ciliares, Zonula Zinnii und hintere Linsenkapsel sind von teils organisiertem, teils frischerem, von Leukocyten mehr oder minder reichlich durchsetzten Exsudat überzogen.

Die Linse selbst blieb von dem Splitter völlig unberührt. Gleichwohl ist die hintere Kapsel zentral in grosser Ausdehnung geborsten. Linsenmassen sind durch den Riss ausgetreten und sind durch reichliche Eiterinfiltration zu einem kugligen Gebilde aufgequollen, das einerseits die Kapselpforte verschliesst, anderseits von zarten Fibrinnetzen begrenzt in den Glaskörper hinein vordringt. In diesem Gebilde wechseln erweichte und zerfallene Linsenmassen mit mehr oder minder dichtgedrängten Eiterkörperchen ab, die durch den Kapselriss und die innerhalb der Kapsel noch vorhandene Linsensubstanz gegen die vordere Kapsel zu vordringen. Die Kerne dieser Leukocyten sind grossenteils noch gut tinktionsfähig.

Iris and Corpus ciliare zeigen starke Hyperämie. In beiden findet sich um die Gefässe, oft in dichter Anordnung, einzellige Infiltration, ebenso in der in toto von der Ora serrata bis zur Papille 
abgelösten Retina, wobei diese Infiltration von vorne nach hinten zu stärker wird, diffus die inneren Schichten in der Umgebung der Gefässe durchsetzt, ja sich stellenweise bis zu den äusseren Körnern erstreckt. Auch die Chorioidea befindet sich in hochgradig hyperämischem Zustand, der in der Nähe des Fremdkörperbettes naturgemäss seinen höchsten Grad erreicht. Die schon in der Iris und dem Corpus ciliare beobachtete Rundzelleninfiltration findet sich in der Aderhaut in besonders charakteristischer Form um die Gefässe der mittleren Schicht ausgeprägt [Befund bei sympathisierender Entzündung $\left.{ }^{1}\right)$ ].

Die Untersuchung auf Mikroorganismen ergab positives Resultat. Die Zugehörigkeit zu einer bestimmten Gattung lässt sich nicht einwandsfrei feststellen, doch mögen wohl am ehesten Staphylocokken in Betracht kommen. Wie aus der Schilderung des bakteriologischen Befundes hervorgeht, fanden sich die Mikroorganismen ausschlesslich innerhalb der Linsenkapsel und direkt hinter dieser, genau auf anatomisch feststellbares Gebiet begrenzt. Die ganze Gegend vom Durchtrittsgebiet des Fremdkörpers durch Corpus ciliare, längs den Processus ciliares und der intakten hinteren Linsenkapsel ist mikrobienfrei. Das Vorhandensein einzelner sich kaum mehr färbender Cokkenhaufen an letzterer gibt jedoch einen Fingerzeig dafür, dass längs des geschilderten Weges eine Cokkeninvasion nach dem hinteren Linsenpol zu stande kam. Nur noch in dessen Gegend gelang der färbetechnische Nachweis, während auf dem übrigen $W$ eg die Mikrobien offenbar schon zu Grunde gegangen sind. Ihre Rolle bei der Ätiologie der Kapselruptur wird erst später im Zusammenhang zu erörtern sein. Auch in den eitrigen Bulbusteilen, besonders im Glaskörper und in dem Gebiet des Fremdkörperbettes finden sich keine Mikroorganismen; entsprechend dem ganzen Befund lässt sich mit Sicherheit ein Vorhandensein von Mikrobien ausser an den oben erwähnten Stellen ausschliessen.

Wie ist nun im vorliegenden Falle auf Grund der Ergebnisse der vorgenommenen und der mitgeteilten experimentellen Untersuchungen die Kapselperforation zu erklären?

Eine direkte Verletzung kann ausgeschlossen werden; ebenso starke primäre Linsenquellung, die zur Kapselberstung führte, da der ganze Prozess für die Entstehung einer quellenden Katarakt ohne vorhergegangene Berstung nicht geeignet war. Auch sind Prozesse

1) E. Fuchs, Über sympathisierende Entzündung, nebst Bemerkungen über seröse traumatische Iritis. v. Graefe's Arch. f. Ophthalm. Bd. LXI. 1905. 
auszuschliessen, wie sie Wagenmann beschreibt, bei denen die Kapsel durch Riesenzellen usuriert wird; diese wurden auch vollkommen vermisst. Per exclusionem bleibt also nur die Annahme einer Erweichung durch den Eiterungsprozess. Hierbei ist nun die Rolle der Mikroorganismen und Eiterkörperchen auseinanderzuhalten. Sowohl bei den berichteten experimentellen Untersuchungen, als auch bei den pathologisch-anatomischen Fällen waren stets Mikrobien mit im Spiel. Dies berechtigt aber keineswegs zu dem Schluss, dass denselben eine wesentliche Bedeutung sicher zuzuschreiben ist, weil man bei experimentellen Untersuchungen den Einfluss einer aseptischen Eiterung auf die Linsenkapsel bisher noch kaum beachtet hat, und weil beim menschlichen Auge aus begreiflichen Gründen die bei weitem grösste Zahl der intraokularen Eiterungen mikrobischen Ursprunges ist. Diese Erwägung gab Anlass, das Verhalten der Kapsel bei aseptischer Eiterung zu untersuchen. In dieser Beziehung bin ich zwar nicht in der Lage, die Ergebnisse eigner Experimente vorzulegen, kann aber kurz als Tatsache berichten, dass es auch bei aseptischer Glaskörpereiterung des Kaninchenauges, welche durch $H g$-Injektionen hervorgerufen wird, zur Perforation der hinteren Kapsel und eitrigen Infiltration der hinteren Corticalis kommen kann.

Diese Beobachtung wurde kürzlich von Prof. Leber an Präparaten von Dr. G. Rindfleisch gemacht, die bei seinen Versuchen über die Entstehung der Hypotonie bei eitriger Chorioiditis gewonnen wurden. Von Rindfleisch(5) wurde damals, da dies nicht im Plane seiner Untersuchungen gelegen hatte, dem Verhalten der Linse in der genannten Richtung keine weitere Aufmerksamkeit geschenkt, und die Präparate gestatten leider auch nicht, den Hergang der Erweichung und Perforation genauer zu verfolgen. Von der oben angegebenen Tatsache kann man sich aber an denselben mit Sicherheit überzeugen.

Es würde höchstens noch der Einwand zu erheben sein, dass die erwähnten Versuche nicht mit den peinlichen Vorsichtsmassregeln zur absolut sicheren Ausschliessung von Mikroorganismen angestellt worden sind. Eine Mitwirkung von Mikroorganismen ist aber sehr unwahrscheinlich, weil das $H g$ für sich allein zweifellos eitrige Entzündung macht und weil seine Gegenwart im Glaskörper die Entwicklung der Mikrobien hätte verhüten müssen, selbst wenn einzelne Keime bei der Injektion mit eingeführt worden wären.

Nach dieser Erfahrung dürfte es gewiss wahrscheinlich sein, dass 
auch bei Eiterungen mikrobischen Ursprunges den Leukocyten die wesentliche Rolle zufällt, dass sie es sind, die durch histolytische Wirkung die Kapsel erweichen und zur Perforation bringen. Hierdurch gewinnt auch der oben berichtete Erklärungsversuch Lebers eine weitere Stuitze.

Man könnte sich also folgende Vorstellung über den Hergang der hier in Rede stehenden sogenannten spontanen Kapselperforation. bilden: Kolonisation von Mikroorganismen in der Linsenkapsel, die dann auf chemotaktischem Wege die Leukocyten herbeizogen und zur Anlagerung an die betreffende Stelle der Linsenkapsel veranlassten. Diesen noch lebensfähigen Wanderzellen kann man eine energische Wirksamkeit, eine reichliche Produktion gewebslösenden Enzyms zuschreiben, welche den bereits abgestorbenen und an Ort und Stelle liegengebliebenen Eiterkörperchen nicht mehr zukommt. Ging die Mikrobienwucherung in der Kapsel und der angrenzenden Linsensubstanz weiter, so musste auch die dadurch angeregte Anlockung histologisch wirksamer Zellen eine gewisse Zeit fortdauern und es konnte so allmählich zu immer tiefer greifender Erweichung und schliesslicher Perforation der Kapsel kommen. Auf diese Art lässt sich auch sehr wohl verstehen, warum in andern Fällen die Linse ganz von Eiter umgeben sein kann, ohne dass sie dadurch in irgend einer Weise angegriffen wird. Man kann sich vorstellen, dass in diesem Fall die Mikrobieninvasion nur den Glaskörper betroffen hat und dass sämtliche in letzterem enthaltenen Eiterkörperchen schon abgestorben und nicht mehr wirkungsfähig waren.

Herrn Professor Th. Leber sage ich für sein stetes Interesse, das er der Arbeit entgegenbrachte, und die Unterstützung, die er mir in jeder Hinsicht dabei zuteil werden liess, meinen wärmsten Dank.

\section{Literaturverzeichnis.}

1) 1876. Sinclair, J, Experimentelle Untersuchungen zur Genese der erworbenen Kapselkatarakt.

2) 1877. Becker, O., Pathologie und Therapie des Linsensystems. GraefeSaemisch, Handbuch d. ges. Augenheilk. Bd. Y. 5. Teil. 1. Aufl.

3) 1879. Haab, O., Tuberkulose des Auges. v. Graefe's Arch. f. Ophthalm. Bd. XXV. 3. Abt.

4) 1880. Deutschmann, Untersuchungen zur Pathogenese der Katarakt. v. Graefe's Arch. f. Ophthalm. Bd. XXVI. 1. Abt. S. $135 \mathrm{ff}$.

5) 1880. Rindfleis ch, G., Experimentelle Untersuchungen über die bei der eitrigen Chorioiditis auftretende Herabsetzung des intraokularen Druckes. v. Graefe's Arch. f. Ophthalm. Bd. XXXVII. 2. Abt. 
68 R. v. Heuss, Spontanruptur der hinteren Linsenkapsel usw.

6) 1883. Becker, 0., Zur Anatomie der gesunden und kranken Linse. Wiesbaden, Bergmann.

7) 1887. Wagenmann, A., Ein Fall von doppelseitiger metastatischer Ophthalmitis im Puerperium durch multiple Streptocokkenembolie. v. Graefe's Arch. f. Ophthalm. Bd. XXXIII. 2. Abt. S 147.

8) 1889. Wagenmann, A., Über die von Operationsnarben und vernarbten Irisvorfällen ausgehende Glaskörpereiterung. v. Graefe's Arch. f. Ophthalm. Bd. XXXV. 4. Abt. S. $137 \mathrm{ff}$.

9) 1890. Vossius, Ein Fall von einseitiger metastatischer Ophthalmie. Zeitschrift f. Geburtshilfe u. Gynäkol. Bd. XVIII. Heft 2.

10) 1891. Leber, Th., Die Entstehung der Entzündung. Kap. XXXVIII.

11) 1892. Wagen $m a n n$, A., Weitere Mitteilungen über die von vernarbten Irisvorfällen ausgehende Glaskörpereiterung. v. Graefe's Arch. f. Ophthalm. Bd. XXXVIII. 1. Abt.

12) 1896. Wagenmann, A., Einiges über Fremdkörperriesenzellen im Auge. v. Graefe's Arch. f. Ophthalm. Bd. XLII. 2. Abt.

13) 1903. Ginsberg, S., Grundriss der pathologischen Histologie des Auges. Berlin 1 .403.

14) 1905. Greeff, J., Auge. 11. Lieferung im Lehrbuch d. spez. pathol. Anatomie von Orth.

15) 1905. Hess, K., Pathologie und Therapie des Linsensystems. GraefeSaemisch, Handbuch d. ges. Augenheilk. Bd. VI. 2. Aufl.

\section{Erklärung der Abbildungen auf Taf. I, Fig. 1 u. 2.}

Fig. 1. Horizontalschnitt des Auges durch die Mitte der Linse.

Fig. 2. Horizontalschnitt von der unteren Bulbushälfte in der Nähe der Eintrittsstelle des Fremdkörpers. Der Pfeil bezeichnet den Weg, den der Fremdkörper in das Innere genommen hat. 


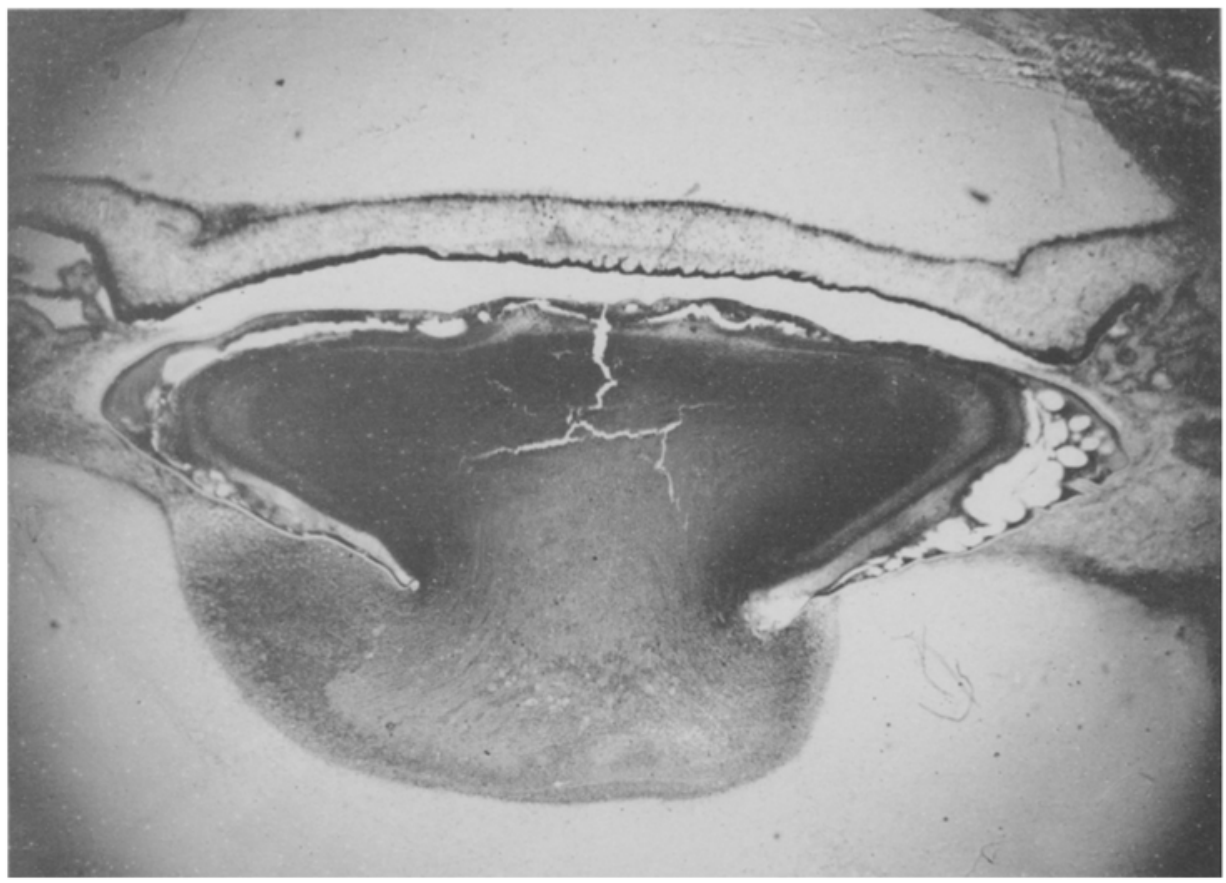

Fig. 1.

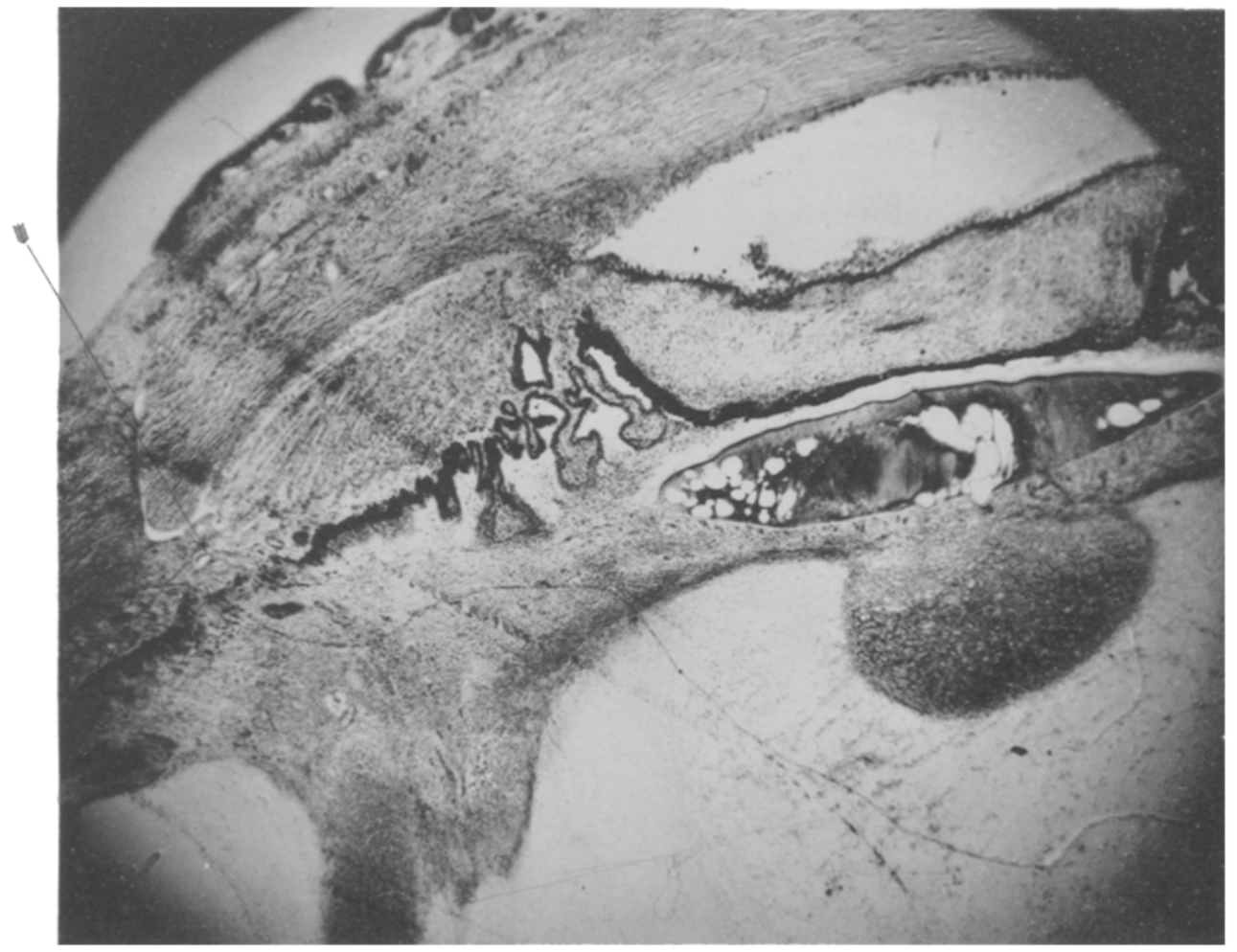

Fig. 2.

Lichtaruck von C. G. Rörex G.m* b. L, Letpatg. 